\title{
Pathways for photoinduced electron transfer in meso-nitro-phenyl-octaethylporphyrins and their chemical dimers
}

\author{
Valentine Knyukshto, Eduard Zenkevich * , Evgenii Sagun, Alexander Shulga, \\ Sergei Bachilo
}

Institute of Molecular and Atomic Physics, Academy of Sciences of Belarus, 70 F. Skaryna Ave., 220072 Minsk, Belarus

Received 20 October 1998; accepted 11 March 1999

\begin{abstract}
The photophysical properties of meso-nitro-phenyl-octaethylporphyrins and their dimers with electron-accepting $\mathrm{NO}_{2}$ groups in the para-, meta- and ortho-positions of the phenyl ring were studied. For the ortho- $\mathrm{NO}_{2}$ case in deaerated toluene at $295 \mathrm{~K}$, strong fluorescence quenching is caused by the intramolecular electron transfer from the porphyrin $\mathrm{S}_{1}$ state in the absence of phenyl ring librations around the single $\mathrm{C}-\mathrm{C}$ bond ('normal' region, non-adiabatic case). $\mathrm{T}_{1}$ state lifetime shortening for the same compounds is explained by thermally activated transitions to upper-lying charge-transfer states of the radical ion pair as well as by the rise of the intersystem crossing $T_{1} \rightarrow S_{0}$ rate constants caused by $T_{1}$ states mixing with charge-transfer states. (C) 1999 Elsevier Science B.V. All rights reserved.
\end{abstract}

\section{Introduction}

Stimulated by biophysical studies of the structure of photosynthetic reaction centres in vivo [1], numerous synthetic models have advanced considerably during the past decade, especially those based on porphyrin or chlorophyll subunits covalently linked to electron acceptors by various spacers, mimicking vectorial electron transfer (ET) processes [2-8]. It has been shown that intracomplex ET has a wide (up to fs) time-scale range, being dependent on the energetic and redox properties of the interacting donoracceptor (D-A) components, their mutual geometry and the $\mathrm{D}-\mathrm{A}$ intercenter distance, the temperature

\footnotetext{
*Corresponding author. E-mail: zenkev@imaph.bas-net.by
}

and polarity of the solvent, as well as on the nature of the spacer.

In this relation, it follows from literature data that the use of an $\mathrm{NO}_{2}$ group as an electron acceptor did not seem to be promising enough because of the relatively small ET rate constants with respect to those obtained for numerous synthetic porphyrinquinone D-A pairs [3,4,9]. Strategies used for linking the porphyrin macrocycle and the $\mathrm{NO}_{2}$ group included the following systems: (1) octaethylporphyrins with meso- $\mathrm{NO}_{2}$ groups [10,11]; (2) tetraphenylporphyrins, TPP, [12] and tetraazaporphyrins [13] with $\beta$-nitro groups; and (3) tetraphenylporphyrins with $\mathrm{NO}_{2}$ groups in the ortho- and para-positions of the phenyl ring [14]. In general, on the basis of the results obtained in Refs. [10-14], one may conclude that at room temperature in non-polar 
solvents, the fluorescence quenching is due to photoinduced ET with rate constants in the range of $k_{\mathrm{et}}^{\mathrm{S}}=(1-5) \times 10^{8} \mathrm{~s}^{-1}$ for all investigated porphyrins with covalently linked nitro groups (free bases and Zn complexes). This relatively small quenching compared with that for quinones may be attributed not only to the lesser electron accepting properties of the nitro group itself but to steric reasons which do not provide the optimal overlap of molecular orbitals for the porphyrin macrocycle and $\mathrm{NO}_{2}$ group determining the electronic coupling term value for ET processes [15]. These factors in detail as well as the possible role of porphyrin triplet states in photoinduced ET processes are still unknown for nitroporphyrins.

In some cases, porphyrin-(electron or energy) acceptor systems $[3-7,14,16]$ and multiporphyrin arrays with or without electron acceptors $[8,9,17-20]$ contain an inserted phenyl spacer between the redox pair or between interacting tetrapyrrole macrocycles. Correspondingly, steric interactions of the phenyl spacer with the connected subunits as well as the $\pi$-electronic nature of the linkage may influence both the deactivation of porphyrin excited states and the electron/energy transfer efficiency. The specific role of steric interactions of meso-phenyls with $\beta$ $\mathrm{CH}_{3}$ pyrrole substituents was mentioned for ET processes in carotenoid-porphyrin-quinone triads [7]. The results obtained in Ref. [16] show that the T-T energy transfer in carotene-porphyrin diads is mediated by a through-bond (superexchange) mechanism involving the $\pi$-electrons of the phenyl linkage. The theoretical model for the bridge-assisted, long-range ET was presented in Ref. [20], showing that even with modest dephasing rates the ET rates become distant independent. Recently, we have found a strong decrease of triplet lifetimes (by $\sim 300-500$ times in degassed toluene at $295 \mathrm{~K}$ ) for mono- and di-mesophenyl substituted octaethylporphyrins, while spectral-kinetic parameters of $\mathrm{S}_{0}$ and $\mathrm{S}_{1}$ states remain unchanged [21]. This quenching was attributed to the porphyrin non-planar dynamic distortions in the excited $\mathrm{T}_{1}$ states, caused by internal librations of the phenyl ring around the single meso $\mathrm{C}-\mathrm{C}$ bond and the interaction of the phenyl ring with the $\pi$-conjugated macrocycle.

To understand the influence of the steric properties of the meso-phenyl spacer and its $\pi$-electron system on the ET pathways and efficiency better, we have prepared a series of meso-phenyl substituted octaethylporphyrins and their chemical phenyl coupled dimers, containing covalently linked one or two $\mathrm{NO}_{2}$ groups in the para-, meta- and ortho-positions of the phenyl spacer (Fig. 1). Here we present the results of steady-state and time-resolved comparative studies of the $S_{1}$ and $T_{1}$ states deactivation for these compounds and the corresponding analogs not having nitro groups.
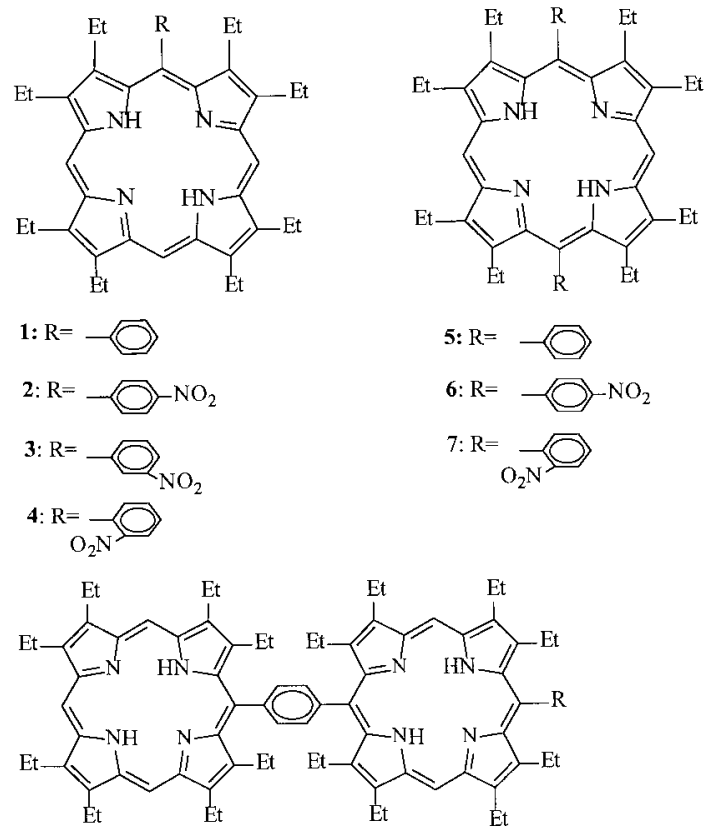

8: $\mathrm{R}=\mathrm{H}$
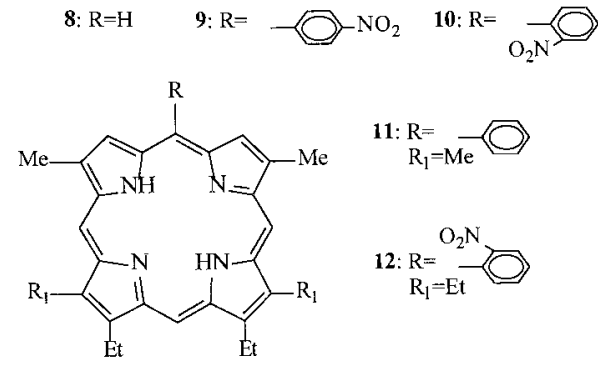

Fig. 1. Chemical structures of the investigated compounds. $\mathbf{1}=$ OEP-Ph; $2=$ OEP-Ph $\left(p-\mathrm{NO}_{2}\right) ; \mathbf{3}=\mathrm{OEP}-\mathrm{Ph}\left(m-\mathrm{NO}_{2}\right) ; \mathbf{4}=\mathrm{OEP}-$ $\mathrm{Ph}\left(o-\mathrm{NO}_{2}\right) ; \quad \mathbf{5}=\mathrm{Ph}-\mathrm{OEP}-\mathrm{Ph} ; \mathbf{6}=\left(p-\mathrm{NO}_{2}\right) \mathrm{Ph}-\mathrm{OEP}-\mathrm{Ph}\left(p-\mathrm{NO}_{2}\right)$; $\mathbf{7}=\left(o-\mathrm{NO}_{2}\right) \mathrm{Ph}-\mathrm{OEP}-\mathrm{Ph}\left(o-\mathrm{NO}_{2}\right) ; \mathbf{8}=$ OEP-Ph-OEP; $9=$ OEP-Ph$\mathrm{OEP}-\mathrm{Ph}\left(p-\mathrm{NO}_{2}\right) ; \quad \mathbf{1 0}=\mathrm{OEP}-\mathrm{Ph}-\mathrm{OEP}-\mathrm{Ph}\left(o-\mathrm{NO}_{2}\right) ; \quad \mathbf{1 1}=$ TMDE$\mathrm{Ph} ; \mathbf{1 2}=\operatorname{TEDM}-\mathrm{Ph}\left(o-\mathrm{NO}_{2}\right)$. 


\section{Experimental}

5-Meso-phenyl substituted compounds, octaethylporphyrin OEP-Ph and the corresponding nitroporphyrins OEP-Ph $\left(p-\mathrm{NO}_{2}\right), \operatorname{OEP}-\mathrm{Ph}\left(\boldsymbol{m}-\mathrm{NO}_{2}\right)$ and OEP-Ph $\left(o-\mathrm{NO}_{2}\right)$, were synthesised and purified according to the method described in Ref. [22]. The same procedure was used for the preparation and characterisation of 5-meso-phenyl substituted tetramethyldiethylporphyrin TMDE-Ph and 5-meso-orthonitro-phenyl substituted tetraethyldimethylporphyrin TEDM-Ph $\left(\boldsymbol{o}-\mathrm{NO}_{2}\right)$. The synthesis of 5,15-diphenyl substituted OEP molecules, Ph-OEP-Ph, $\left(\boldsymbol{p}\right.$-NO $\left.\mathbf{N}_{2}\right)$ $\mathrm{Ph}-\mathrm{OEP}-\mathrm{Ph}\left(p-\mathrm{NO}_{2}\right)$ and (o-NO$) \mathrm{Ph}-\mathrm{OEP}-\mathrm{Ph}(o-$ $\mathrm{NO}_{2}$ ), was carried out on the basis of the methods described in Refs. [23,24]. The porphyrin chemical dimers OEP-Ph-OEP, OEP-Ph-OEP-Ph $\left(\boldsymbol{p}-\mathrm{NO}_{2}\right)$ and OEP-Ph-OEP-Ph $\left(\boldsymbol{o}-\mathrm{NO}_{2}\right)$, were synthesised according to known methods [17-19]. The corresponding compounds with one or two $\mathrm{NO}_{2}$ groups were synthesised on the basis of the methods cited above.

All spectroscopic experiments, $S_{1}$ and $T_{1}$ states decay measurements, as well as the determination of singlet oxygen generation quantum yields were performed using commercial and hand-made laboratory equipment described in Refs. [25,26]. When studying $\mathrm{T}_{1}$ states parameters in liquid solutions at $295 \mathrm{~K}$, porphyrin concentrations of $\sim 10^{-6} \mathrm{M}$ were used for the $\mathrm{T}-\mathrm{T}$ annihilation diminishing. Most results at $295 \mathrm{~K}$ were obtained in toluene (Spectroscopic Grade) unless otherwise noted. Methylcyclohexanetoluene (6:1) glassy rigid matrices were used at 77 $\mathrm{K}$. In order to study the excited states quenching by dissolved oxygen, the comparative kinetic measurements were carried out in deaerated samples (5-7 freeze-pump-thaw cycles, purging down to $10^{-5}$ Torr pressure). All experiments for every sample were completed within $1-2 \mathrm{~h}$ following preparation.

\section{Results and discussion}

\subsection{Spectral properties}

At $295 \mathrm{~K}$ in toluene, absorption and fluorescence spectra of para- and meta-nitro substituted porphyrins remain practically the same with respect to those for the corresponding meso-phenyl substituted compounds without nitro groups (Table 1). In the case of the ortho- $\mathrm{NO}_{2}$ substitution, the Stokes shift remains the same but the electronic spectra are slightly red-shifted by $\Delta \lambda \sim 1-6 \mathrm{~nm}$. In addition, a relative decrease of the $\mathrm{Q}(0,0)$ bands intensities both in fluorescence and absorption spectra with respect to the corresponding intensities of vibronic $\mathrm{Q}(1,0)$

Table 1

Absorption and emission parameters at room temperature and low temperatures

\begin{tabular}{|c|c|c|c|c|c|c|c|c|c|}
\hline No. & Compound & $\begin{array}{l}\text { Absorpt. } \\
\Lambda^{\text {soret }} \\
(\mathrm{nm}) \\
295 \mathrm{~K}\end{array}$ & $\begin{array}{l}\text { Absorpt. } \\
\lambda^{\text {Soret }} \\
(\mathrm{nm}) \\
77 \mathrm{~K}\end{array}$ & $\begin{array}{l}\text { Absorpt. } \\
\lambda_{0-0} \\
(\mathrm{~nm}) \\
295 \mathrm{~K}\end{array}$ & $\begin{array}{l}\text { Fluoresc. } \\
\lambda_{0-0} \\
(\mathrm{~nm}) \\
295 \mathrm{~K}\end{array}$ & $\begin{array}{l}\text { Absorpt. } \\
\lambda_{0-0} \\
(\mathrm{~nm}) \\
77 \mathrm{~K}\end{array}$ & $\begin{array}{l}\text { Fluoresc. } \\
\lambda_{0-0} \\
(\mathrm{~nm}) \\
77 \mathrm{~K}\end{array}$ & $\begin{array}{l}\text { Phosph. } \\
\lambda_{0-0} \\
(\mathrm{~nm}) \\
77 \mathrm{~K}\end{array}$ & $\begin{array}{l}\Delta E\left(\mathrm{~S}_{1}-\mathrm{T}_{1}\right) \\
\left(\mathrm{cm}^{-1}\right) \\
77 \mathrm{~K}\end{array}$ \\
\hline 1 & OEP-Ph & 403 & 402 & 626 & 628 & 620 & 621 & 790 & 3450 \\
\hline 2 & $\operatorname{OEP}-\mathrm{Ph}\left(p-\mathrm{NO}_{2}\right)$ & 403 & 405 & 627 & 628 & 620 & 621 & 790 & 3450 \\
\hline 3 & $\operatorname{OEP}-\mathrm{Ph}\left(m-\mathrm{NO}_{2}\right)$ & 403 & 405 & 628 & 630 & 621 & 622 & 792 & 3470 \\
\hline 4 & $\operatorname{OEP}-\mathrm{Ph}\left(o-\mathrm{NO}_{2}\right)$ & 404 & 405 & 629 & 634 & 623 & 624 & 797 & 3490 \\
\hline 5 & Ph-OEP-Ph & 411 & 411 & 629 & 633 & 623 & 624 & 806 & 3620 \\
\hline 6 & $\left(p-\mathrm{NO}_{2}\right) \mathrm{Ph}-\mathrm{OEP}-\mathrm{Ph}\left(p-\mathrm{NO}_{2}\right)$ & 412 & 411 & 631 & 635 & 625 & 626 & 795 & 3400 \\
\hline 7 & $\left(o-\mathrm{NO}_{2}\right) \mathrm{Ph}-\mathrm{OEP}-\mathrm{Ph}\left(o-\mathrm{NO}_{2}\right)$ & 410 & 412 & 635 & 639 & 627 & 628 & 815 & 3650 \\
\hline 8 & OEP-Ph-OEP & 413 & 410 & 625 & 626 & 625 & 626 & 803 & 3520 \\
\hline 9 & OEP-Ph-OEP-Ph $\left(p-\mathrm{NO}_{2}\right)$ & 418 & 413 & 631 & 638 & 623 & 625 & 810 & 3650 \\
\hline 10 & OEP-Ph-OEP-Ph $\left(o-\mathrm{NO}_{2}\right)$ & 419 & 413 & 632 & 640 & 626 & 628 & 815 & 3650 \\
\hline 11 & TMDE-Ph & 403 & 402 & 627 & 630 & 622 & 623 & 796 & 3490 \\
\hline 12 & TEDM-Ph $\left(o-\mathrm{NO}_{2}\right)$. & 403 & 404 & 630 & 635 & 624 & 625 & 801 & 3520 \\
\hline
\end{tabular}

Experimental data at $295 \mathrm{~K}$ were obtained in toluene; at $77 \mathrm{~K}$ a glassy matrix of methylcyclohexane-toluene mixture (6:1) was used. $\Delta E\left(\mathrm{~S}_{1}-\mathrm{T}_{1}\right)$ is the energy gap between locally excited $\mathrm{S}_{1}$ and $\mathrm{T}_{1}$ states. 
bands was observed followed by a half-width increase (by $\sim 1.5$ times) of the pure electronic transition bands (Fig. 2). Similar tendencies have been observed for 5-nitrooctaethylporphyrins [10], $\beta$ nitro-tetra-para-tolylporphyrins [12] and TPP with four $\mathrm{NO}_{2}$ groups in ortho- and para-positions [14]. These spectral changes have been connected with the well-known fact that electron withdrawing substituents on the periphery of the porphyrin cause shifts to longer wavelength of the visible and Soret bands [12]. Table 1 shows that spectral properties of the OEP-Ph-OEP dimer are scarcely affected by nitro substitution.

Fig. 3 compares the transient triplet-triplet absorption spectra in the near IR region of ortho- and para-nitro substituted OEP-Ph molecules with those

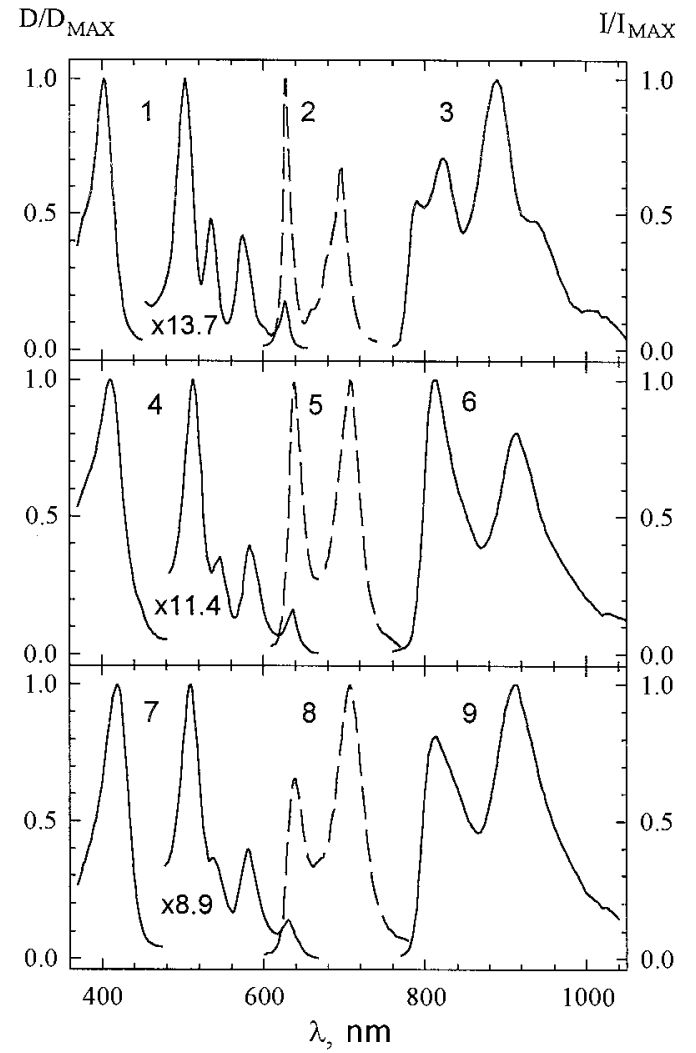

Fig. 2. Absorption $(1,4,7)$ and fluorescence $(2,5,8)$ spectra in toluene at $295 \mathrm{~K}$ and phosphorescence spectra $(3,6,9)$ in methylcyclohexane-toluene mixture (6:1) at $77 \mathrm{~K}$ : $\mathbf{O E P}-\mathbf{P h}(1,2,3)$; $\left(o-\mathrm{NO}_{2}\right) \mathrm{Ph}-\mathrm{OEP}-\mathrm{Ph}\left(\boldsymbol{o}-\mathrm{NO}_{2}\right)(4,5,6)$; and OEP-Ph-OEP$\mathbf{P h}\left(o-\mathrm{NO}_{2}\right)(7,8,9)$.

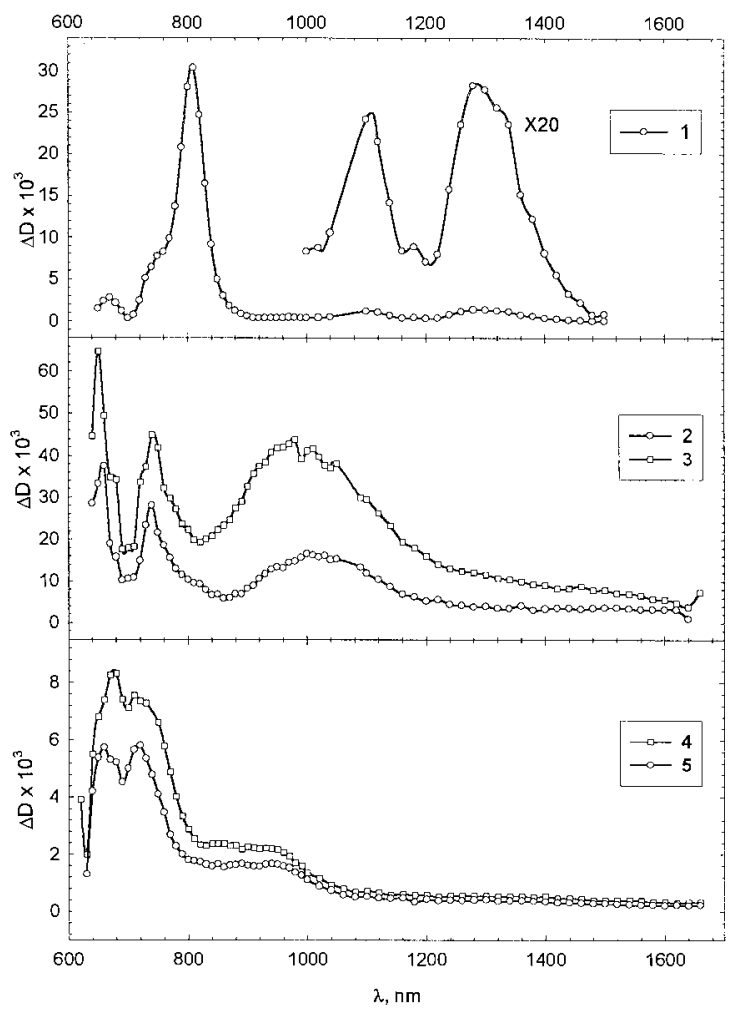

Fig. 3. Transient triplet-triplet absorption spectra (optical densities $\Delta D)$ following a $25 \mathrm{~ns}$ laser flash excitation of OEP-Ph $\left(o-\mathrm{NO}_{2}\right)(1)$, OEP-Ph $\left(p-\mathrm{NO}_{2}\right)(2)$, OEP-Ph (3), OEP-Ph $\left(\boldsymbol{o}-\mathbf{C H}_{3}\right)$ (4) and OEP (5) under the same experimental conditions (deaerated toluene solution at $295 \mathrm{~K}, \lambda_{\mathrm{exc}}=532 \mathrm{~nm}$ ).

of the corresponding compounds without nitro groups. According to our previous results [21], the noticeable difference between the $\mathrm{T}-\mathrm{T}$ absorption spectra of OEP and OEP-Ph (Fig. 3, curves 5 and 3) may be connected with the non-planar conformational dynamics of OEP-Ph in the $T_{1}$ state due to internal librations of the phenyl ring around the single $\mathrm{C}-\mathrm{C}$ bond. In such a situation, the energies of higher excited triplet states and extinction coefficients may differ for the compounds of these two types. It can be seen from Fig. 3 that T-T absorption spectra are partially the same for $\mathbf{O E P}-\mathbf{P h}\left(\boldsymbol{p}-\mathrm{NO}_{2}\right)$ and OEP-Ph, being somewhat red-shifted for the nitroporphyrin relative to those of OEP-Ph (Fig. 3, curves 2 and 3 ). The spectral similarity in this case is explained by the fact [21] that the presence of bulky substituents in the para- or meta-positions of the 
phenyl ring in molecules of the OEP-Ph type does not influence their $T_{1}$ state characteristics relative to those of OEP-Ph. In the ortho-phenyl substituted $\operatorname{OEP}-\mathbf{P h}\left(\boldsymbol{o}-\mathrm{CH}_{3}\right)$ molecule containing a bulky $\mathrm{CH}_{3}$ group, the non-planar dynamic conformations of the porphyrin macrocycle do not result in the locally excited $\mathrm{T}_{1}$ state [21], and its $\mathrm{T}-\mathrm{T}$ absorption spectrum practically coincides with that of a planar OEP molecule (Fig. 3, curves 4 and 5). In this relation, the transient T-T spectrum for OEP-Ph $\left(\boldsymbol{o}-\mathrm{NO}_{2}\right)$ differs strikingly from those for both $\mathrm{OEP}-\mathrm{Ph}\left(\boldsymbol{o}-\mathbf{C H}_{3}\right)$ and parent OEP molecules (Fig. 3, curves 1, 4 and 5). In addition, the relative intensities of OEP-Ph $\left(\boldsymbol{o}-\mathrm{NO}_{2}\right)$ $\mathrm{T}-\mathrm{T}$ absorption bands show a noticeable dependence on the solvent polarity. This means that locally excited $\mathrm{T}_{1}$ states of nitro-phenyl substituted octaethylporphyrins are sensitive to the localisation of the $\mathrm{NO}_{2}$ group and their deactivation and spectral properties are thought to be connected with ET reactions.

\subsection{Photophysics and photochemistry}

The main photophysical parameters for mesonitro-phenyl substituted compounds as well as for the corresponding analogs without $\mathrm{NO}_{2}$ groups are collected in Table 2. On the basis of these data and structural properties of the compounds 1-12 (Fig. 1) the following findings were revealed:

(1) At $295 \mathrm{~K}$ in degassed toluene, fluorescence quantum yields $\left(\varphi_{\mathrm{F}}^{0}\right)$ and lifetimes $\left(\tau_{\mathrm{S}}^{0}\right)$ for paraand meta- $\mathrm{NO}_{2}$ containing OEP-Ph molecules and their dimer OEP-Ph-OEP do not differ strikingly from those for the corresponding compounds which lack nitro groups. A small fluorescence quenching is still observed with rate constants of $k_{\mathrm{et}}^{\mathrm{S}}=1.2 \times 10^{6}$ $1.0 \times 10^{7} \mathrm{~s}^{-1}<1 / \tau_{\mathrm{S}}^{0}$, where $\tau_{\mathrm{S}}^{0}$ corresponds to the $\mathrm{S}_{1}$ state decay of OEP type compounds without $\mathrm{NO}_{2}$ groups. A minimal fluorescence quenching was found for the meta- $\mathrm{NO}_{2}$ substitution in comparison with the para- $\mathrm{NO}_{2}$ case. In addition, for para- and meta$\mathrm{NO}_{2}$-phenyl substituted OEPs a noticeable decrease of $\mathrm{T}_{1}$ state lifetimes $\left(\tau_{\mathrm{T}}^{0}\right)$ is observed, and the $\tau_{\mathrm{T}}^{0}$ shortening for OEP-Ph $\left(\boldsymbol{m}-\mathbf{N O}_{2}\right)$ is smaller relative to that of OEP-Ph $\left(p-\mathrm{NO}_{2}\right)$. For OEP-Ph $\left(p-\mathrm{NO}_{2}\right)$, the $\tau_{\mathrm{T}}^{0}$ value is reduced by 2.1 times relative to that for OEP-Ph. The existence of the second nitro group in $\left(p-\mathrm{NO}_{2}\right) \mathbf{P h}-\mathrm{OEP}-\mathrm{Ph}\left(\boldsymbol{p}-\mathrm{NO}_{2}\right)$ leads to a shorten- ing of $\tau_{\mathrm{T}}^{0}$ by 5.5 times with respect to $\tau_{\mathrm{TR}}^{0}=16.5 \mu \mathrm{s}$ found for the parent Ph-OEP-Ph molecule. For the dimer OEP-Ph-OEP( $\boldsymbol{p}$-NO $\left.\mathbf{N O}_{2}\right), \mathrm{T}_{1}$ state quenching is not observed with respect to $\tau_{\mathrm{TR}}^{0}$ value for OEP-PhOEP.

(2) For ortho-nitro-phenyl substituted OEPs and their dimers quantum yields $\varphi_{\mathrm{F}}$ decrease by 12-25 times and $\tau_{\mathrm{S}}^{0}$ shortening amounts to $\sim 100$ times under same conditions, that is the rate constant of $S_{1}$ state quenching ranges up to the value of $k_{\text {et }}^{\mathrm{S}}=9.5 \times$ $10^{9} \mathrm{~s}^{-1}$. The observed $\mathrm{S}_{1}$ state quenching is substantially greater than that found for numerous covalently linked porphyrin- $\mathrm{NO}_{2}$ systems for which $k_{\mathrm{et}}^{\mathrm{S}}$ $\leq(1-5) \times 10^{8} \mathrm{~s}^{-1}$ in non-polar solvents at room temperature [10-14].

Ortho-nitro-phenyl substituted OEPs and their dimers are also characterised by the essential enhancement of the non-radiative deactivation of $\mathrm{T}_{1}$ states. For OEP-Ph $\left(\boldsymbol{o}-\mathrm{NO}_{2}\right), \tau_{\mathrm{T}}^{0}$ decreases by 5.3 times with respect to the $\tau_{\mathrm{T}}^{0}$ value for OEP-Ph. In $\left(o-\mathrm{NO}_{2}\right) \mathrm{Ph}-\mathrm{OEP}-\mathrm{Ph}\left(o-\mathrm{NO}_{2}\right)$, with two nitro groups in the opposite meso-phenyls, the $\tau_{\mathrm{T}}^{0}$ value is reduced by 33 times relative to that for Ph-OEP-Ph. In reality, $\tau_{\mathrm{T}}^{0}$ shortening in these nitroporphyrins ranges up to $\sim 1000-1500$ times if one takes into account steric hindrance effects resulting in triplet long decays $\left(\tau_{\mathrm{TR}}^{0} \approx 700-750 \mu \mathrm{s}\right)$ for the reference $\operatorname{OEP}-\mathrm{Ph}\left(\boldsymbol{o}-\mathrm{CH}_{3}\right)$ molecule with the bulky orthophenyl substituent [21]. However, in the dimer OEPPh-OEP-Ph $\left(o-\mathrm{NO}_{2}\right) \tau_{\mathrm{T}}^{0}$ shortening by $\sim 5$ times relative to $\tau_{\mathrm{TR}}^{0}=2.45 \mu \mathrm{s}$ of the parent OEP-Ph-OEP compound reflects the real $\mathrm{T}_{1}$ state quenching. Actually, in the last case, torsion librations of the phenyl spacer around the single $\mathrm{C}-\mathrm{C}$ bond and its interactions with two porphyrin subunits in OEP-Ph-OEP are not eliminated by the insertion of bulky substituents in the ortho-position at the second phenyl ring (see compounds 8 and 10, Fig. 1). Fig. 4 shows that experimental points 4, 7, 10 for all ortho-nitro substituted compounds do not fit in the correlative dependence $\ln \left(k_{\mathrm{T}}^{0}\right)=\ln \left(1 / \tau_{\mathrm{T}}^{0}\right)=f\left(\sum r^{*}\right)$ constructed on the basis of the influence of steric effects only.

(3) The enhanced nonradiative deactivation of excited states in nitroporphyrins manifests itself in their interaction with $\mathrm{O}_{2}$ in toluene at $295 \mathrm{~K}$. For the para- and meta- $\mathrm{NO}_{2}$ case the second-order rate constants of $\mathrm{S}_{1}$ state quenching by $\mathrm{O}_{2}$ do not depend 
Table 2

Photophysical and photochemical data in toluene at $295 \mathrm{~K}$ and in a glassy transparent matrix of methylcyclohexane-toluene mixture (6:1) at $77 \mathrm{~K}$

\begin{tabular}{|c|c|c|c|c|c|c|c|c|c|c|c|c|c|c|c|}
\hline Compound & $\begin{array}{l}\tau_{\mathrm{S}} \\
\text { (ns) } \\
295 \mathrm{~K}\end{array}$ & $\begin{array}{l}\tau_{\mathrm{S}}^{0} \\
(\mathrm{~ns}) \\
295 \mathrm{~K}\end{array}$ & $\begin{array}{l}\tau_{\mathrm{S}} \\
(\mathrm{ns}) \\
77 \mathrm{~K}\end{array}$ & $\begin{array}{l}\varphi_{\mathrm{F}}{ }^{\mathrm{a}} \\
295 \mathrm{~K}\end{array}$ & $\begin{array}{l}\varphi_{\mathrm{F}} \\
77 \mathrm{~K}\end{array}$ & $\begin{array}{l}\varphi_{\mathrm{P}} \\
\left(\times 10^{4}\right) \\
77 \mathrm{~K}\end{array}$ & $\begin{array}{l}\tau_{\mathrm{T}} \\
(\mathrm{ms}) \\
77 \mathrm{~K}\end{array}$ & $\begin{array}{l}\tau_{\mathrm{T}} \\
(\mathrm{ns}) \\
295 \mathrm{~K}\end{array}$ & $\begin{array}{l}\tau_{\mathrm{T}}^{0} \\
(\mathrm{~s}) \\
295 \mathrm{~K}\end{array}$ & $\gamma_{\mathrm{T}}$ & $\gamma_{\Delta}$ & $\begin{array}{l}k_{\mathrm{S}}^{\mathrm{b}} \\
\left(10^{9} \mathrm{M}^{-1} \mathrm{~s}^{-1}\right)\end{array}$ & $\begin{array}{l}k_{\mathrm{T}}^{\mathrm{b}} \\
\left(10^{9} \mathrm{M}^{-1} \mathrm{~s}^{-1}\right)\end{array}$ & $\begin{array}{l}k_{\mathrm{et}}^{\mathrm{S} \mathrm{c}} \\
\left(\mathrm{s}^{-1}\right)\end{array}$ & $\begin{array}{l}k_{\mathrm{q}}^{\mathrm{Tc}} \\
\left(\mathrm{s}^{-1}\right)\end{array}$ \\
\hline OEP-Ph & 11.2 & 16.0 & 21.0 & 0.05 & 0.09 & 1.9 & 14.5 & 410 & 4.0 & 0.80 & 0.55 & 14.2 & 1.2 & & \\
\hline $\operatorname{OEP}-\mathrm{Ph}\left(p-\mathrm{NO}_{2}\right)$ & 10.7 & 15.4 & 21.3 & 0.05 & 0.06 & 1.5 & 13.5 & 710 & 1.9 & - & 0.3 & 15.8 & 0.5 & $2.4 \times 10^{6}$ & $2.8 \times 10^{5}$ \\
\hline $\operatorname{OEP}-\mathrm{Ph}\left(m-\mathrm{NO}_{2}\right)$ & 11.5 & 15.7 & - & 0.07 & 0.09 & 3.0 & 16.9 & 470 & 3.0 & - & - & 12.9 & 1.0 & $1.2 \times 10^{6}$ & $8 \times 10^{5}$ \\
\hline OEP-Ph $\left(o-\mathrm{NO}_{2}\right)$ & $0.105^{\mathrm{d}}$ & 0.105 & 20.2 & 0.002 & 0.06 & 1.4 & 13.0 & 700 & 0.75 & $\sim 0.1$ & $<0.01$ & - & - & $9.5 \times 10^{9}$ & $1.3 \times 10^{6}$ \\
\hline Ph-OEP-Ph & 9.9 & 13.0 & - & 0.05 & 0.06 & 0.9 & 10.3 & 380 & 16.5 & - & - & 13.4 & 1.4 & & \\
\hline $\begin{array}{l}\left(p-\mathrm{NO}_{2}\right) \mathrm{Ph} \text {-OEP- } \\
\mathrm{Ph}\left(p-\mathrm{NO}_{2}\right)\end{array}$ & 10.5 & 12.6 & - & 0.07 & 0.08 & 2.3 & 10.1 & 690 & 3.0 & 0.65 & 0.55 & 9.0 & 0.6 & $3.0 \times 10^{6}$ & $2.7 \times 10^{5}$ \\
\hline $\begin{array}{l}\left(o-\mathrm{NO}_{2}\right) \mathrm{Ph}-\mathrm{OEP}- \\
\mathrm{Ph}\left(o-\mathrm{NO}_{2}\right)\end{array}$ & $0.10^{\mathrm{d}}$ & 0.10 & 16.0 & 0.001 & 0.07 & 1.6 & 11.0 & 400 & 0.5 & $\sim 0.2$ & $<0.01$ & - & 0.3 & $9.5 \times 10^{9}$ & $2.0 \times 10^{6}$ \\
\hline OEP-Ph-OEP & 8.2 & 11.2 & - & 0.06 & - & - & 8.9 & 840 & 2.45 & 0.95 & 0.25 & 18.3 & 0.45 & & \\
\hline $\begin{array}{l}\text { OEP-Ph-OEP- } \\
\mathrm{Ph}\left(p-\mathrm{NO}_{2}\right)\end{array}$ & 7.8 & 10.1 & 15.0 & 0.04 & 0.07 & 1.7 & 8.2 & 865 & 2.4 & - & 0.3 & 15.8 & 0.4 & $1.0 \times 10^{7}$ & $<1 \times 10^{5}$ \\
\hline $\begin{array}{l}\text { OEP-Ph-OEP- } \\
\mathrm{Ph}\left(o-\mathrm{NO}_{2}\right)\end{array}$ & 0.3 & 0.3 & 16.0 & 0.005 & 0.04 & 0.9 & 8.2 & 450 & 0.5 & - & $<0.01$ & - & - & $3.2 \times 10^{9}$ & $1.6 \times 10^{6}$ \\
\hline TMDE-Ph & 11.3 & 17.1 & - & 0.06 & 0.09 & 1.8 & 16 & 265 & 1640 & 0.80 & 0.80 & 16.7 & 2.1 & & \\
\hline $\operatorname{TEDM}-\mathrm{Ph}\left(o-\mathrm{NO}_{2}\right)$ & 1.7 & 1.7 & - & 0.01 & 0.07 & 2.2 & 12.9 & 315 & 195 & - & - & - & 1.8 & $5.0 \times 10^{8}$ & $4.5 \times 10^{3}$ \\
\hline
\end{tabular}

All abbreviations and symbols are defined in the text.

${ }^{\mathrm{a}}$ The rise of $\varphi_{\mathrm{F}}$ in degassed toluene solutions at $295 \mathrm{~K}\left(\varphi_{\mathrm{F}}^{0}\right)$ is the practically same relative to that of $\tau_{\mathrm{S}}$.

${ }^{\mathrm{b}}$ Second-order rate constants $k_{\mathrm{S}}$ and $k_{\mathrm{T}}$ for quenching of $\mathrm{S}_{1}$ and $\mathrm{T}_{1}$ states by $\mathrm{O}_{2}$ were obtained using the Stern-Volmer equation $\tau^{0} / \tau=1+k C \tau^{0}$ (a), where $\tau^{0}$ corresponds to $\mathrm{S}_{1}$ or $\mathrm{T}_{1}$ state decay in the absence of $\mathrm{O}_{2}, C=1.8 \times 10^{-3} \mathrm{M}$ is the $\mathrm{O}_{2}$ concentration in toluene at $295 \mathrm{~K}[11,27]$.

${ }^{c}$ Calculations of the rate constants of $\mathrm{S}_{1}$ and $\mathrm{T}_{1}$ states quenching for nitroporphyrins were carried out on the base of measured lifetimes using the well-known formula $k=1 / \tau^{0}-1 / \tau_{\mathrm{R}}^{0}(\mathrm{~b})$, where $\tau_{\mathrm{R}}^{0}$ is the reference sample lifetime; in the case of $\mathrm{T}_{1}$ state quenching the $\tau_{\mathrm{TR}}^{0}$ values corresponding to unquenched $\mathrm{T}_{1}$ states were found to be $700-750 \mu \mathrm{s}$ using the correlative dependence $\ln \left(k_{\mathrm{T}}^{0}\right)=\ln \left(1 / \tau_{\mathrm{T}}^{0}\right)=f\left(\sum r^{*}\right)$ (Fig. 4) for compounds without ortho- $\mathrm{NO}_{2}$ group but with the ortho-substituent characterized by the same overlap geometrical parameter $\sum r^{*}=5.11 \AA$.

${ }^{\mathrm{d}}$ Decays were measured using the picosecond spectrometer, error $= \pm 7 \%$. 


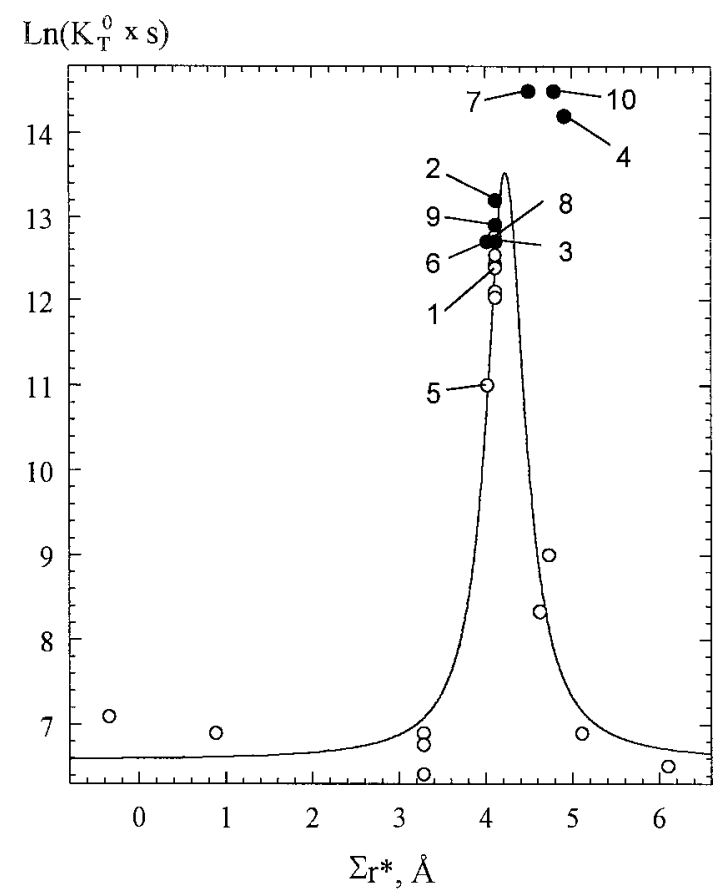

Fig. 4. The correlative dependence of the triplet state deactivation rate constants $k_{\mathrm{T}}^{0}$ on the overlap geometrical parameter $\sum r^{*}$, $\ln \left(k_{\mathrm{T}}^{0}\right)=\ln \left(1 / \tau_{\mathrm{T}}^{0}\right)=f\left(\sum r^{*}\right)$, for octaalkylporphyrins and their dimers being studied in deoxygenated toluene at $295 \mathrm{~K}$. Values of $\sum r^{*}$ were calculated using the formula $\sum r^{*}=\left(r_{\mathrm{w} 1}^{x}+r_{\mathrm{w} 2}^{x}\right)-d_{x}$ $+\left(r_{\mathrm{w} 1}^{y}+r_{\mathrm{w} 2}^{y}\right)-d_{y}$ [21]. The effective van der Waals radii $\left(r_{\mathrm{w}}\right)$ values for interacting substituents were taken from a handbook of chemistry; intercenter distances $\left(d_{x}, d_{y}\right)$ for these substituents were estimated for the hypothetical coplanar arrangement of the porphyrin and phenyl planes derived from the optimised structures of the compounds (HyperChem software, release 4, semiempirical methods AM1 and PM3) [21]. Experimental points $\bigcirc$ correspond to the triplet state deactivation rate constants $k_{\mathrm{T}}^{0}$ for meso-phenyl substituted compounds without nitro group, investigated in details earlier [21]; experimental points were obtained for meso-nitrophenyl substituted octaethylporphyrins in this investigation. Numbers 1-10 correspond to compounds with the chemical structures shown in Fig. 1.

on the position of $\mathrm{NO}_{2}$ group $\left(k_{\mathrm{S}}=(1.3-1.6) \times 10^{10}\right.$ $\mathrm{M}^{-1} \mathrm{~s}^{-1}$ ) and are close to those for OEP-Ph and other OEPs without nitro groups. In the ortho- $\mathrm{NO}_{2}$ case, we have not be able to estimate $k_{\mathrm{S}}$ values because of strong $\tau_{\mathrm{S}}$ shortening. As for $\mathrm{T}_{1}$ state quenching by $\mathrm{O}_{2}$, a decrease of $k_{\mathrm{T}}$ values was observed for all meso-nitro-phenyl substituted OEPs relative to those for compounds which lack $\mathrm{NO}_{2}$ groups. In para-nitro substituted compounds, the decrease of $k_{\mathrm{T}}$ values amounts to 1.5-2.5 times being the smallest one for the dimer OEP-Ph-OEP$\mathbf{P h}\left(\boldsymbol{p}-\mathrm{NO}_{2}\right)$, while for meta- $\mathrm{NO}_{2}$ substitution only a minor influence on $k_{\mathrm{T}}$ was found. In $\left(\boldsymbol{o}-\mathrm{NO}_{2}\right) \mathbf{P h}$ $\operatorname{OEP}-\operatorname{Ph}\left(\boldsymbol{o}-\mathrm{NO}_{2}\right), k_{\mathrm{T}}$ is reduced by $\sim 5$ times.

The reduction of $\mathrm{T}_{1}$ state lifetimes in meso-nitrophenyl substituted OEPs and their dimers leads to a pronounced decrease of quantum yields $\left(\gamma_{\Delta}\right)$ of the singlet oxygen ${ }^{1} \Delta_{\mathrm{g}}$ generation. For $\operatorname{OEP}-\mathbf{P h}(\boldsymbol{p}$ $\left.\mathbf{N O}_{2}\right), \gamma_{\Delta}$ is reduced by 2 times relative to that of OEP-Ph. Because of a strong $\mathrm{T}_{1}$ state shortening in the ortho-nitro case $\left(\tau_{\mathrm{T}}^{0} \approx 500-750 \mathrm{~ns}\right)$, we have not be able to detect the singlet oxygen emission at normal atmospheric pressure directly. The low values of $k_{\mathrm{T}}=0.45 \times 10^{9} \mathrm{M}^{-1} \mathrm{~s}^{-1}$ and $\gamma_{\Delta}=0.25$ obtained for the dimer OEP-Ph-OEP may be connected with a possible increase of the dimer oxidation potential or with a rise of the bimolecular rate constant for the dissociation of the collision complex $\left[{ }^{3}\right.$ Dimer $\left.\cdots{ }^{3} \mathrm{O}_{2}\right] \rightarrow{ }^{3}$ Dimer $+{ }^{3} \mathrm{O}_{2}$ without $\mathrm{T}-\mathrm{T}$ energy transfer and ${ }^{1} \Delta_{\mathrm{g}}$ formation [11].

(4) When transition from TMDE-Ph to TEDM$\mathbf{P h}\left(\boldsymbol{o}-\mathrm{NO}_{2}\right.$ ) (neither molecule has bulky $\mathrm{C}_{2} \mathrm{H}_{5}$ substituents at the $\beta$-pyrrolic positions neighbouring the phenyl ring, see Fig. 1, compounds 11 and 12) the decrease of the $\tau_{\mathrm{S}}^{0}$ and $\tau_{\mathrm{T}}^{0}$ lifetimes is not so pronounced as that observed for the OEP-Ph $\rightarrow$ OEP$\mathbf{P h}\left(\boldsymbol{o}-\mathrm{NO}_{2}\right)$ case. For TEDM-Ph $\left(o-\mathrm{NO}_{2}\right)$, the $k_{\mathrm{et}}^{\mathrm{S}}$ value is less by $\sim 20$ times and the $k_{\mathrm{q}}^{\mathrm{T}}$ is smaller by $\sim 300$ times relative to the corresponding parameters for $\operatorname{OEP}-\mathrm{Ph}\left(\mathrm{o}-\mathrm{NO}_{2}\right)$.

(5) The nonradiative deactivation of $S_{1}$ states for nitrooctaethylporphyrins is strongly enhanced in polar solvents (Table 3). At the same time, in glassy matrices at $77 \mathrm{~K}$, the excited states quenching is fully absent for all the systems, and the main photophysical parameters for $S_{1}$ and $T_{1}$ states are fairly typical ones for planar porphyrins in low-temperature organic glasses $[12,21,25]$.

If one takes into account the fact that meso-phenyl substitution in OEPs and their dimers does not change the nonradiative deactivation of the $S_{1}$ states [21] and absorption spectra are not perturbed by the nitro substitution (Fig. 2), the observed fluorescence quenching may be explained properly by ET processes from the porphyrin to the nitro group. As was mentioned above, the minimal quenching effect was observed for meta- $\mathrm{NO}_{2}$ substitution with respect to 
Table 3

Fluorescence parameters of meso-nitro-phenyl-octaethylporphyrins and their chemical dimers in solvents of various polarity (295 K, solutions at atmospheric pressure)

\begin{tabular}{|c|c|c|c|c|c|c|}
\hline \multirow[t]{2}{*}{ Compound } & \multicolumn{2}{|c|}{$\begin{array}{l}\text { Toluene } \\
\varepsilon=2.379 \\
n=1.4969\end{array}$} & \multicolumn{2}{|c|}{$\begin{array}{l}\text { Acetone } \\
\varepsilon=20.7 \\
n=1.3586\end{array}$} & \multicolumn{2}{|c|}{$\begin{array}{l}\text { Acetonitrile } \\
\varepsilon=35.9 \\
n=1.3441\end{array}$} \\
\hline & $\varphi_{\mathrm{F}}$ & $\begin{array}{l}\tau_{\mathrm{S}} \\
(\mathrm{ns})\end{array}$ & $\varphi_{\mathrm{F}}$ & $\begin{array}{l}\tau_{\mathrm{S}} \\
(\mathrm{ns})\end{array}$ & $\varphi_{\mathrm{F}}$ & $\begin{array}{l}\tau_{\mathrm{S}} \\
(\mathrm{ns})\end{array}$ \\
\hline OEP-Ph & 0.05 & 11.2 & - & - & 0.06 & 11.3 \\
\hline $\mathrm{OEP}-\mathrm{Ph}\left(p-\mathrm{NO}_{2}\right)$ & 0.05 & 10.7 & 0.015 & - & 0.002 & $\sim 0.02^{\mathrm{a}}$ \\
\hline OEP-Ph $\left(m-\mathrm{NO}_{2}\right)$ & 0.07 & 11.5 & 0.02 & 3.7 & 0.003 & 0.6 \\
\hline $\mathrm{OEP}-\mathrm{Ph}\left(o-\mathrm{NO}_{2}\right)$ & 0.002 & 0.105 & - & - & 0.001 & $\sim 0.005^{\mathrm{a}}$ \\
\hline$\left(p-\mathrm{NO}_{2}\right) \mathrm{Ph}-\mathrm{OEP}-\mathrm{Ph}\left(p-\mathrm{NO}_{2}\right)$ & 0.07 & 10.5 & 0.03 & - & $0.005^{\mathrm{b}}$ & - \\
\hline OEP-Ph-OEP-Ph $\left(p-\mathrm{NO}_{2}\right)$ & 0.04 & 7.8 & 0.025 & - & $0.006^{\mathrm{c}}$ & - \\
\hline TEDM -Ph $\left(o-\mathrm{NO}_{2}\right)$ & 0.01 & 1.7 & - & - & 0.001 & - \\
\hline
\end{tabular}

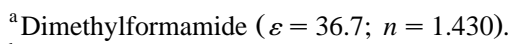

${ }^{\mathrm{b}}$ Pyridine-acetonitrile mixture $(1: 10)$.

${ }^{\mathrm{c}}$ Toluene-acetonitrile mixture (1:10).

that of the para- $\mathrm{NO}_{2}$ case. The same tendency has been noticed for the T-T energy transfer in diads in which carotenoid was covalently linked to a TPP macrocycle at the ortho-, meta- and para-positions of a meso aromatic ring [16]. According to arguments presented in Ref. [16], it seems reasonable to suggest that the smallest quenching effect for the meta- $\mathrm{NO}_{2}$ substitution in our case is due to the fact that for both the HOMO and the LUMO, the orbital density is greater at the ortho- and para-positions than it is at the meta-position of the phenyl spacer. Thus, the electronic coupling of the nitro group and the porphyrin, as mediated by the superexchange interaction [16], will also be greater at the para-position. In this relation, for $\mathbf{O E P}-\mathbf{P h}\left(\boldsymbol{m}-\mathrm{NO}_{2}\right)$ and $\operatorname{OEP}-\mathbf{P h}\left(p-\mathrm{NO}_{2}\right)$ as well as for dimers with the same substitution, photoinduced ET processes are affected by through-bond interactions [15] and may be considered as bridge-assisted reactions [20]. In the dimer OEP-Ph-OEP-Ph $\left(\boldsymbol{o}-\mathrm{NO}_{2}\right)$, the $k_{\text {et }}^{\mathrm{S}}$ value is reduced by three times relative to that of the corresponding monomer OEP-Ph(o-NO $\left.\mathbf{N}_{2}\right)$. This reduction may be connected with the competing $\mathrm{S}-\mathrm{S}$ energy transfer between covalently linked porphyrin macrocycles (rate constants $F^{\mathrm{SS}}=(1.9-5.0) \times 10^{9}$ $\left.\mathrm{s}^{-1}[8,28]\right)$.

The high effective photoinduced ET in all ortho$\mathrm{NO}_{2}$ substituted compounds is partly due to the influence of steric effects. In this case, the steric hindrance of neighbouring bulky substituents in the $\beta$-positions of pyrrole rings and ortho-substituents of the meso-phenyl spacer significantly restricts internal librations of the phenyl ring about the single $\mathrm{C}-\mathrm{C}$ bond. Hence, the ortho-nitro phenyl octaethylporphyrin moieties are expected to be relatively rigid structures. The molecular mechanics calculations (HyperChem software, release 4, semiempirical AM1 and PM3 methods [21]) for OEP-Ph(o-NO$)$ show that preferable dihedral angles between the porphyrin plane $(\mathrm{P})$, the phenyl plane $(\mathrm{Ph})$ and the nitro group plane $\left(\mathrm{NO}_{2}\right)$ are the following: $\alpha(\mathrm{P}, \mathrm{Ph}) \approx 85 \pm 4^{\circ}$, $\beta\left(\mathrm{NO}_{2}, \mathrm{Ph}\right) \approx 80 \pm 4^{\circ}$ and $\theta\left(\mathrm{NO}_{2}, \mathrm{P}\right) \approx 60 \pm 5^{\circ}$. This geometry favours the overlap of molecular orbitals of the porphyrin macrocycle and the $\mathrm{NO}_{2}$ group and leads to strong electronic coupling, resulting in the effective, direct through-space ET from the locally excited $\mathrm{S}_{1}$ state to the low-lying CT state $[15,20]$. In contrast to $\mathbf{O E P}-\mathbf{P h}\left(\boldsymbol{o}-\mathbf{N O}_{2}\right)$, there are no bulky $\mathrm{C}_{2} \mathrm{H}_{5}$ substituents at the $\beta$-pyrrolic positions flanking the ortho-nitro phenyl in TEDM-Ph(o$\mathrm{NO}_{2}$ ) (Fig. 1, compounds 4 and 12). Because of the reduction of van der Waals spheres overlap for the interacting substituents in the last case [21], it leads to larger amplitudes of the phenyl libration motions about the $\mathrm{C}-\mathrm{C}$ bond and a corresponding decrease of the electronic coupling term for the ET processes. In fact, the low-effective ET in tetra-ortho-phenyl TPP [14] may be explained similarly. Nevertheless, in 
toluene at $295 \mathrm{~K}$, the rate constant $k_{\mathrm{et}}^{\mathrm{S}}=5.0$ $\times 10^{8} \mathrm{~s}^{-1}$ for TEDM-Ph(o-NO $\left.\mathbf{N}_{2}\right)$ is higher than that of tetra-ortho-phenyl TPP $\left(k_{\text {et }}^{\mathrm{S}}=1.5 \times 10^{8} \mathrm{~s}^{-1}\right.$ in benzene [14]). This fact is explained by different oxidation potentials for OEP and TPP and will be discussed below.

\subsection{Quantitative interpretation of electron transfer processes}

In the condensed phase, the hypothetical singlet excited CT state energies may be reasonably estimated according to the well-known formula [2-4]:

$E_{\mathrm{CT}}=e\left(E_{1 / 2}^{\mathrm{ox}}-E_{1 / 2}^{\mathrm{red}}\right)-W$,

where $E_{1 / 2}^{\mathrm{ox}}$ is the $\mathrm{D}$ one-electron oxidation potential, $E_{1 / 2}^{\text {red }}$ is the A one-electron reduction potential, $W=$ $e^{2} / 4 \pi \varepsilon_{0} \varepsilon_{\mathrm{st}} r_{\mathrm{DA}}$ is the Coulombic interaction energy between the ions at the distance $r_{\mathrm{DA}}$ in the $\mathrm{D}-\mathrm{A}$ pair, where $e$ is the electron charge and $\varepsilon_{0}$ is the permittivity of free space. On the basis of the $W$ value for $\mathrm{Zn}$-porphyrin-acceptor systems in acetonitrile (the static dielectric constant $\varepsilon_{\mathrm{st}}=35.9$ ) [29] and the intercenter distance $r_{\mathrm{DA}}=5.7 \AA$ between the porphyrin and the ortho- $\mathrm{NO}_{2}$ group (found for the HyperChem optimised OEP-Ph $\left(\boldsymbol{o}-\mathrm{NO}_{2}\right)$ structure) we obtained $W \approx 0.08 \mathrm{eV}$ in our case. Then using known values of redox potentials (vs. SCE in dimethylformamide, $\left.\varepsilon_{\mathrm{st}}=36.7\right)$ for $\mathbf{O E P}\left(E_{1 / 2}^{\mathrm{ox}}=\right.$ $0.81 \mathrm{eV}$ [30]), TPP ( $E_{1 / 2}^{\mathrm{ox}}=1.08 \mathrm{eV}$ [27]) and nitro benzene $\left(E_{1 / 2}^{\mathrm{red}}=-1.08 \mathrm{eV}\right.$ [27]), we found that $E_{\mathrm{CT}}=1.8 \mathrm{eV}\left(14500 \mathrm{~cm}^{-1}\right)$ for $\operatorname{OEP}-\mathbf{P h}\left(\boldsymbol{o}-\mathbf{N O}_{2}\right)$ and $E_{\mathrm{CT}}=2.1 \mathrm{eV}\left(16900 \mathrm{~cm}^{-1}\right)$ for $\operatorname{TPP}\left(\boldsymbol{o}-\mathbf{N O}_{2}\right)$.

Accordingly, in TPP $\left(\boldsymbol{o}-\mathrm{NO}_{2}\right)$ the predicted CT state is higher by $\sim 0.18 \mathrm{eV}\left(1440 \mathrm{~cm}^{-1}\right)$ than the locally excited $\mathrm{S}_{1}$ state $\left(E_{\mathrm{S} 1}=15460 \mathrm{~cm}^{-1}=1.92\right.$ $\mathrm{eV}$ [14]). Hence, the additional deactivation of $S_{1}$ state may occur only at the expense of the thermal population of the radical ion pair state or through an increase in the nonradiative transition rate constant caused by mixing with the high-lying CT state $[2,31]$. In contrast, for OEP-Ph $\left(\boldsymbol{o}-\mathrm{NO}_{2}\right)$ the predicted CT state is low-lying by $\sim 0.17 \mathrm{eV}\left(1370 \mathrm{~cm}^{-1}\right)$ relative to its $S_{1}$ state $\left(E_{\mathrm{S} 1}=15870 \mathrm{~cm}^{-1}=1.97 \mathrm{eV}\right.$, in dimethylformamide). Thus, in the latter case, the nonradiative deactivation of the locally excited $S_{1}$ state may be due to the direct population of low- lying CT state with a high efficiency. From structural considerations, it follows that $E_{1 / 2}^{\text {ox }}(\mathbf{T P P})>$ $E_{1 / 2}^{\mathrm{ox}}(\mathbf{T E D M})>E_{1 / 2}^{\mathrm{ox}}(\mathbf{O E P})$ which should lead to the intermediate position of the CT state: $E_{\mathrm{CT}}[\mathbf{T P P}(\boldsymbol{o}-$ $\left.\left.\mathrm{NO}_{2}\right)\right]>E_{\mathrm{CT}}\left[\operatorname{TEDM}\left(o-\mathrm{NO}_{2}\right)\right]>E_{\mathrm{CT}}\left[\operatorname{OEP}\left(o-\mathrm{NO}_{2}\right)\right]$ Therefore, with the same steric factors resulting in the close values of the electronic coupling terms for $\operatorname{TEDM}-\mathbf{P h}\left(o-\mathrm{NO}_{2}\right)$ and $\mathbf{T P P}\left(o-\mathrm{NO}_{2}\right)$ molecules the CT state energy lowering for $\operatorname{TEDM}-\mathbf{P h}\left(\boldsymbol{o}-\mathrm{NO}_{2}\right)$ may lead to a strengthening of the nonradiative deactivation of the $S_{1}$ state in this compound, which is consistent with experimental findings.

At high temperatures, the rate constant $k_{\mathrm{et}}^{\mathrm{S}}$ for endergonic or moderately exergonic non-adiabatic ET occurring within the 'normal' region is given by the following expressions $[15,2,4,31]$ :

$k_{\mathrm{et}}^{\mathrm{S}}=\frac{2 \pi}{\hbar} \frac{V^{2}}{\left(4 \pi \lambda k_{\mathrm{B}} T\right)^{1 / 2}} \exp \left(\frac{\Delta G^{*}}{k_{\mathrm{B}} T}\right)$,

$\Delta G^{*}=\frac{\left(\Delta G^{\mathrm{o}}+\lambda\right)^{2}}{4 \lambda}$,

where $k_{\mathrm{B}}$ is Boltzmann's constant, $T$ is the temperature, $h$ is Planck's constant, $V$ is the electronic coupling term between the electronic wavefunctions of the reactant and product states, $\lambda=\lambda_{\text {in }}+\lambda_{\text {solv }}$ is the Gibbs reorganisation energy determined by the nuclear $\lambda_{\text {in }}$ and solvent $\lambda_{\text {solv }}$ reorganisation energies, $\Delta G^{\mathrm{o}}$ is the standard Gibbs energy of the ET reaction and $\Delta G^{*}$ is the Marcus-Gibbs activation energy. For steric reasons, OEP-Ph(o-NO $\left.\mathbf{N}_{2}\right)$ is expected to have a relatively rigid structure. Thus, we may assume that $\lambda_{\text {in }} \approx 0.2 \mathrm{eV}$, which seems appropriate for porphyrin macrocycles that do not undergo substantial geometry changes upon one-electron redox events $[3,4,32]$. The $\lambda_{\text {solv }}$ value is often calculated using the formula $[4,15,31,32]$ :

$\lambda_{\text {solv }}=\frac{e^{2}}{4 \pi \varepsilon_{0}}\left[\frac{1}{2 r_{\mathrm{D}}}+\frac{1}{2 r_{\mathrm{A}}}-\frac{1}{r_{\mathrm{DA}}}\right]\left[\frac{1}{\varepsilon_{\mathrm{op}}}-\frac{1}{\varepsilon_{\mathrm{st}}}\right]$,

where $r_{\mathrm{D}}$ and $r_{\mathrm{A}}$ are $\mathrm{D}$ and $\mathrm{A}$ radii, respectively, $\varepsilon_{\text {op }}=n^{2}$ is the optical dielectric constant, $n$ is the refraction index and $\varepsilon_{\text {st }}$ is the static dielectric constant of the solvent. Based on literature data and the HyperChem optimised structure of OEP-Ph $\left(o-N_{2}\right)$, 
the following parameters $r_{\mathrm{D}}=5 \AA[3,29], r_{\mathrm{A}}=3.5$ $\AA$ and $r_{\text {DA }}=5.7 \AA$ were obtained. Correspondingly, in acetonitrile the derived value of the outer reorganisation energy is $\lambda_{\text {solv }}=0.5 \mathrm{eV}$ and the total reorganisation energy is $\lambda=0.7 \mathrm{eV}$.

The standard Gibbs energy of the ET reaction is given by the formula $[4,15,31]$ :

$\Delta G^{\mathrm{o}}=e\left(E_{\mathrm{ox}}^{1 / 2}-E_{\mathrm{red}}^{1 / 2}\right)-W-E_{\mathrm{S}_{1}}$.

For $\operatorname{OEP}-\operatorname{Ph}\left(\boldsymbol{o}-\mathrm{NO}_{2}\right)$ this value is equal to $\Delta G^{\mathrm{o}}=$ $-0.16 \mathrm{eV}$, and the Marcus-Gibbs activation energy (3) corresponds to the value of $\Delta G^{*}=0.1 \mathrm{eV}$. Since $\left|-\Delta G^{\circ}\right|<\lambda$ in this case, the ET process may be assigned to the 'normal' region of the Marcus parabolic dependence, $\log k_{\mathrm{et}}^{\mathrm{S}}=f\left(-\Delta G^{\mathrm{o}}\right)$ [15].

Based on the picosecond transient absorption measurements of $\mathrm{S}_{1}$ state decay for OEP-Ph $\left(\boldsymbol{o}-\mathbf{N O}_{2}\right)$ in dimethylformamide at $295 \mathrm{~K}$ (Table 3), an ET rate constant of $k_{\mathrm{et}}^{\mathrm{S}} \approx 2 \times 10^{11} \mathrm{~s}^{-1}$ was estimated. Thus, using expression (2) and taking into consideration the parameters of $\lambda$ and $\Delta G^{*}$ obtained as well as the experimental value of $k_{\mathrm{et}}^{\mathrm{S}}$, we estimated the electronic coupling matrix element $V$ to be $\sim 190$ $\mathrm{cm}^{-1}$ in dimethylformamide at $295 \mathrm{~K}$. It is known [33] that ET reactions are non-adiabatic by LandauZener criteria if they satisfy the following relationship

$4 \pi^{2} V^{2} / h \omega\left(2 \lambda k_{\mathrm{B}} T\right)^{1 / 2}<1$,

where $\omega \approx 100 \mathrm{~cm}^{-1}$ for typical low-frequency solvent motions at $300 \mathrm{~K}$. It follows from the Eq. (6) that at a total reorganisation energy of $\lambda=0.7 \mathrm{eV}$ for OEP-Ph $\left(o-N_{2}\right)$, the electronic coupling matrix element $V<130 \mathrm{~cm}^{-1}$, which does not differ greatly from $V \approx 190 \mathrm{~cm}^{-1}$ obtained using Eq. (2). Thus, assuming realistic errors for $\lambda$ and $\Delta G^{\circ}$ estimates one may conclude that at $295 \mathrm{~K}$ in polar media the $\mathrm{S}_{1}$ state quenching in OEP-Ph(o-NO$)$ seems to be the limiting case of the non-adiabatic ET with a possible manifestation of some adiabacity effects in strongly polar solvents. Additionally, in the case of $V>100 \mathrm{~cm}^{-1}$ one may use the adiabaticity parameter of Rips and Jortner [34] in order to evaluate the solvent dynamics influence on the ET rate:

$K=4 \pi V^{2} \tau_{\mathrm{L}} / \hbar \lambda$,

where $\tau_{\mathrm{L}}$ is the longitudinal relaxation time of the solvent ( $0.4 \mathrm{ps}$ for dimethylformamide). By use of $V$ and $\lambda$ values for OEP-Ph( $\left.\boldsymbol{o}-\mathrm{NO}_{2}\right)$ in dimethylformamide at $295 \mathrm{~K}$, we estimated $K \leq 7$. It means that in this case the ET process may be solvent controlled. However, for OEP-Ph(o-NO $\left.\mathrm{NO}_{2}\right)$ in non-polar or slightly polar media, as well as for $\mathbf{O E P}-\mathbf{P h}(\boldsymbol{p}$ $\left.\mathrm{NO}_{2}\right)$ and OEP-Ph $\left(\boldsymbol{m}-\mathrm{NO}_{2}\right)$ in both polar and nonpolar solvents, the photoinduced ET from porphyrin $\mathrm{S}_{1}$ states is essentially non-adiabatic.

\subsection{Formation and deactivation of locally excited triplet states at room temperature}

Table 2 shows that the rate constants $k_{\mathrm{q}}^{\mathrm{T}}$ of $\mathrm{T}_{1}$ state quenching are lower by 3-4 orders of magnitude relative to the corresponding $k_{\mathrm{et}}^{\mathrm{S}}$ values. From the data obtained for OEP-Ph, it follows that the rate constant of the nonradiative intersystem crossing $\mathrm{S}_{1}$ $\rightarrow \mathrm{T}_{1}$ is $r=5.0 \times 10^{7} \mathrm{~s}^{-1}$ and the fluorescence rate constant is $f=4.5 \times 10^{6} \mathrm{~s}^{-1}$. Thus, in OEP-Ph $(\boldsymbol{o}$ $\left.\mathbf{N O}_{2}\right) k_{\mathrm{et}}^{\mathrm{S}}=9.5 \times 10^{9} \mathrm{~s}^{-1} \gg r, f$ and a direct population of the $\mathrm{T}_{1}$ state has a low probability. It manifests itself in the drastic decrease of the quantum yields of both the nonradiative intersystem crossing $\mathrm{S}_{1} \rightarrow \mathrm{T}_{1}\left(\gamma_{\mathrm{T}}\right)$ and the singlet oxygen generation $\left(\gamma_{\Delta}\right)$ for ortho-nitro phenyl substituted octaethylporphyrins (Table 2).

Using phosphorescence spectral data (Fig. 1) we estimated the $\mathrm{T}_{1}$ state energy for $\operatorname{OEP}-\mathbf{P h}\left(\boldsymbol{o}-\mathbf{N O}_{2}\right)$ to be $E_{\mathrm{T}}=1.56 \mathrm{eV}\left(12550 \mathrm{~cm}^{-1}\right)$. Accordingly, the excited singlet $\mathrm{CT}$ state of the radical ion pair is upper-lying by $\sim 0.24 \mathrm{eV}$ relative to that for $\mathrm{T}_{1}$ state (Fig. 5). Besides, when analysing the temperature dependence of the rate constant $k_{\mathrm{q}}^{\mathrm{T}}$ for $\mathbf{O E P}-\mathbf{P h}(\boldsymbol{o}$ $\mathrm{NO}_{2}$ ) in the form of an Arrhenius-type expression [32] we found that the activation energy in the polar toluene-acetone $(3: 1)$ mixture corresponds to the value of $\Delta E_{\mathrm{a}}=0.20 \mathrm{eV}$. The $\mathrm{D}-\mathrm{A}$ pair is certainly more conformationally rigid, the spin-exchange energy is negligible and the spin rephasing between the singlet and triplet radical ion pairs is rather effective with the corresponding rate constants of $k_{13} \approx k_{31} \approx$ $5.0 \times 10^{7} \mathrm{~s}^{-1}$ [4] (Fig. 5). This means that the population of the locally excited $\mathrm{T}_{1}$ state may take place from the upper-lying triplet radical ion pair state ${ }^{3}\left[\mathrm{OEP}^{+} \cdots \mathrm{NO}_{2}^{-}\right]$or directly from the singlet radical ion pair state ${ }^{1}\left[\mathrm{OEP}^{+} \ldots \mathrm{NO}_{2}^{-}\right]$. This reasonable assumption was confirmed by the experimental findings showing that the decrease of the 


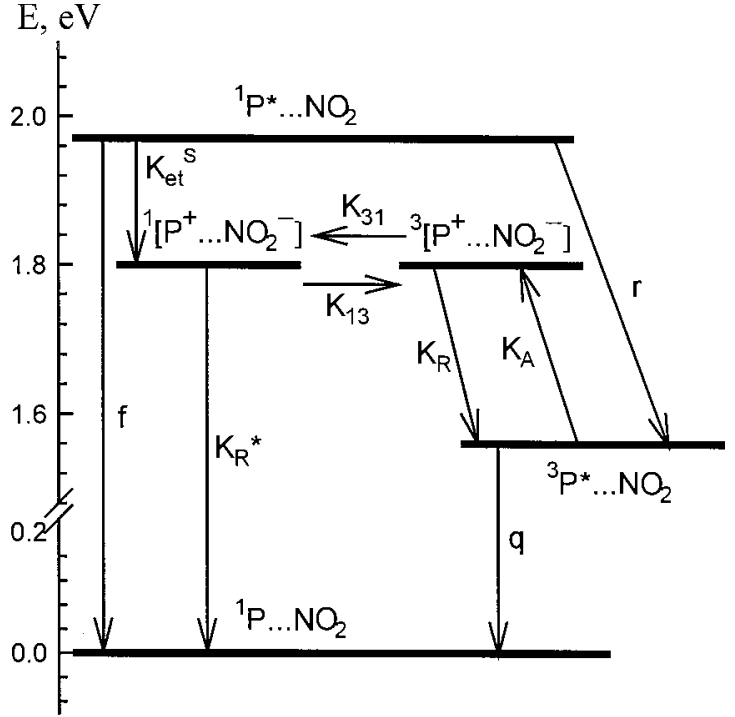

Fig. 5. Schematic energy level diagram for low-lying locally excited singlet $\left({ }^{1} \mathrm{P}^{*} \cdots \mathrm{NO}_{2}\right)$ and triplet $\left({ }^{3} \mathrm{P}^{*} \cdots \mathrm{NO}_{2}\right)$ states, charge-transfer states $\left({ }^{1}\left[\mathrm{P}^{+} \cdots \mathrm{NO}_{2}^{-}\right],{ }^{3}\left[\mathrm{P}^{+} \cdots \mathrm{NO}_{2}^{-}\right]\right)$and decay pathways of OEP-Ph $\left(\boldsymbol{o}-\mathbf{N O}_{2}\right)$ in acetonitrile at $295 \mathrm{~K}$. The rate constants are as follows: $f$, fluorescence; $r$, intersystem crossing from the singlet to the triplet state, $\mathrm{S}_{1} \rightarrow \mathrm{T}_{1} ; q$, non-radiative intersystem crossing to the ground state, $\mathrm{T}_{1} \rightarrow \mathrm{S}_{0} ; k_{\mathrm{R}}^{*}$, charge recombination from the singlet radical ion pair; $k_{\mathrm{R}}$, charge recombination from the triplet radical ion pair; $k_{\mathrm{et}}^{\mathrm{S}}$, electron transfer from the singlet state; $k_{13}, k_{31}$, spin rephasing between the singlet and triplet radical ion pairs; $k_{\mathrm{A}}$, the thermally activated population of the triplet radical ion pair.

fluorescence quantum $\left(\varphi_{\mathrm{F}}^{\mathrm{o}} / \varphi_{\mathrm{F}} \approx 25\right)$ is not parallel to the decrease of the intersystem crossing quantum yield $\left(\gamma_{\mathrm{T}}^{0} / \gamma_{\mathrm{T}} \approx 8\right)$ when going from OEP-Ph to $\operatorname{OEP}-\mathbf{P h}\left(\boldsymbol{o}-\mathrm{NO}_{2}\right)$ in toluene at $295 \mathrm{~K}$. Correspondingly, the non-radiative deactivation of $\operatorname{OEP}-\mathbf{P h}(\boldsymbol{o}$ $\mathbf{N O}_{2}$ ) $T_{1}$ state may occur via the thermal activation of the radical ion pair states followed by the charge recombination from these states to the ground state:

$$
\begin{aligned}
\left(\mathrm{T}_{1}\right)\left[{ }^{3} \mathrm{P} \cdots \mathrm{NO}_{2}\right] & \underset{K_{\mathrm{R}}}{\stackrel{K_{\mathrm{A}}}{\rightleftharpoons}}\left[\mathrm{P}^{+} \cdots \mathrm{NO}_{2}^{-}\right] \\
& \left.\stackrel{K_{13}}{\rightleftharpoons} 11 \mathrm{P}^{+} \cdots \mathrm{NO}_{2}^{-}\right] \\
& \stackrel{K_{\mathrm{R}}^{*}}{\rightarrow}\left[\mathrm{P} \cdots \mathrm{NO}_{2}\right]\left(\mathrm{S}_{0}\right)
\end{aligned}
$$

(rate constants are defined in Fig. 5). In addition, the $\tau_{\mathrm{T}}$ shortening in $\mathbf{O E P}-\mathbf{P h}\left(\boldsymbol{o}-\mathbf{N O}_{2}\right)$ may also be due to the rise of the intersystem crossing $T_{1} \rightarrow \mathrm{S}_{0}$ rate constant caused by a perturbation to the locally excited $\mathrm{T}_{1}$ state by mixing with upper-lying $\mathrm{CT}$ states of the radical ion pair.

\section{Conclusions}

We have shown that both the $S_{1}$ and $T_{1}$ states of meso-nitro-phenyl octaethylporphyrins and their chemical dimers are quenched relative to the corresponding states of the parent compounds without nitro groups. The direct ET processes are responsible for the observed fluorescence quenching, and ET rate constants are in a reasonable agreement with the predictions of Marcus theory. The population of the locally excited low-lying $\mathrm{T}_{1}$ state may take place from the upper-lying triplet or singlet CT states. The non-radiative deactivation of the $\mathrm{T}_{1}$ state may be due to both the thermal activation of the CT states and the rise of the intersystem crossing $\mathrm{T}_{1} \rightarrow \mathrm{S}_{0}$ rate constant.

With respect to other nitroporphyrins, this study demonstrates that steric hindrance effects and the nature of the linkage between D and A influence on the efficiency and the mechanism of photoinduced ET. Our results also show that the photophysical consequences of the dynamic non-planarity of meso-phenyl-substituted octaethylporphyrins in the $\mathrm{T}_{1}$ state should be included in the quantitative estimation of the quenching efficiency for the corresponding porphyrins with $\mathrm{NO}_{2}$ groups and more complex arrays on their base.

\section{Acknowledgements}

This research was supported by the NFBR of Belarus (Grant No. Ph 96-92). We are grateful to Dr. S. Tikhomirov for picosecond transient absorption measurements of $S_{1}$ state decays. We thank also $\mathrm{Mr}$. D. Starukhin for his assistance in temperature experiments on the $T_{1}$ state quenching.

\section{References}

[1] J. Deisenhofer, O. Epp, K. Miki, R. Huber, H. Michel, J. Mol. Biol. 180 (1989) 385.

[2] M.R. Wasielewski, G.L. Gaines III, M.P. O’Neil, W.A. Svec, 
M.P. Niemczyk, L. Prodi, D. Gosztola, in: N. Mataga, T. Okada, H. Masuhara (Eds.), Dynamics and Mechanisms of Photoinduced Transfer and Related Phenomena, Elsevier, New York, 1992, p. 87.

[3] M.R. Wasielewski, Chem. Rev. 92 (1992) 435.

[4] D.D. Fraser, J.R. Bolton, J. Phys. Chem. 98 (1994) 1626.

[5] A. Harriman, J.-P. Sauvage, Chem. Soc. Rev. 25 (1996) 41.

[6] A. Osuka, S. Marumo, N. Mataga, S. Taniguchi, T. Okada, I. Yamazaki, Y. Nishimura, T. Ohno, K. Nozaki, J. Am. Chem. Soc. 118 (1996) 155.

[7] D. Kuciauskas, P.A. Liddell, S.-C. Hung, S. Lin, S. Stone, G.R. Seely, A.L. Moore, T.A. Moore, D. Gust, J. Phys. Chem. B 101 (1997) 429.

[8] E.I. Zenkevich, A.M. Shulga, S.M. Bachilo, U. Rempel, J. von Richthofen, Ch. von Borczyskowski, J. Lumin. 76/77 (1998) 354.

[9] J.L. Sessler, M.R. Johnson, T.-Y. Lin, Tetrahedron 45 (1989) 4784.

[10] S.S. Dvornikov, T.F. Kachura, V.N. Knyukshto, V.A. Kuzmitzkii, K.N. Solov'ev, I.K. Shushkevich, Opt. Spectrosk. 61 (1986) 1228, in Russian.

[11] V.A. Ganzha, G.P. Gurinovich, B.M. Dzhagarov, G.D. Egorova, E.I. Sagun, A.M. Shulga, Zh. Prikl. Spektrosk. 50 (1989) 618, in Russian.

[12] D. Gust, T.A. Moore, D.K. Luttrull, G.R. Seely, E. Bittersmann, R.V. Bensasson, M. Rougee, E.J. Land, F.C. De Schryver, M. Van der Auweraer, Photochem. Photobiol. 51 (1990) 419.

[13] I.K. Shushkevich, V.M. Kopranenkov, S.S. Dvornikov, K.N. Solov'ev, Zh. Prikl. Spektrosk. 46 (1987) 538, in Russian.

[14] A. Harriman, R.G. Hosie, J. Chem. Soc., Faraday Trans. 277 (1981) 1695.

[15] R.A. Marcus, Rev. Modern Phys. 65 (1993) 599.

[16] D. Gust, T.A. Moore, A.L. Moore, C. Devados, P.A. Liddell, R. Hermant, R.A. Nieman, L.G. Demanche, J.M. DeGraziano, I. Gouni, J. Am. Chem. Soc. 114 (1992) 3590.
[17] A.V. Chernook, A.M. Shulga, E.I. Zenkevich, U. Rempel, Ch. von Borczyskowski, J. Phys. Chem. 100 (1996) 1918.

[18] J.L. Sessler, V.L. Capuano, A. Harriman, J. Am. Chem. Soc. 115 (1993) 4618.

[19] A. Osuka, N. Tanabe, S. Nakajima, K. Maruyama, J. Chem. Soc., Perkin Trans. 2 (1996) 199.

[20] W.B. Davis, M.R. Wasielewski, M.A. Ratner, J. Phys. Chem. 101 (1997) 6158.

[21] V.N. Knyukshto, E.I. Zenkevich, E.I. Sagun, A.M. Shulga, S.M. Bachilo, Chem. Phys. Lett. 297 (1998) 97.

[22] A.M. Shulga, G.P. Gurinovich, Dokl. Akad. Nauk BSSR 25 (1981) 55, in Russian.

[23] M.J. Gunter, L.N. Mander, J. Org. Chem. 46 (1981) 4792.

[24] R. Young, C.K. Chang, J. Am. Chem. Soc. 107 (1985) 898.

[25] E.I. Zenkevich, E.I. Sagun, V.N. Knyukshto, A.M. Shulga, A.F. Mironov, O.A. Efremova, R. Bonnett, S. Phinda Songca, M. Kassem, J. Photochem. Photobiol. B: Biol. 33 (1996) 171.

[26] S.M. Bachilo, J. Photochem. Photobiol. A: Chem. 91 (1995) 111.

[27] S.L. Murrov, I. Carmichael, G.L. Hug, Handbook of Photochemistry, Marcel Dekker, New York, 1993, p. 269.

[28] E.I. Zenkevich, A.M. Shulga, A.V. Chernook, E.I. Sagun, G.P. Gurinovich, Proc. Indian Acad. Sci., Chem. Sci. 107 (1995) 795.

[29] N. Barboy, J. Feitelson, J. Phys. Chem. 88 (1984) 1065.

[30] J. Fuhrhop, K. Kadish, D. Davis, J. Am. Chem. Soc. 95 (1973) 40.

[31] G.J. Kavarnos, Fundamentals of Photoinduced Electron Transfer, ch. 6, VCH, New York, 1993, p. 287.

[32] A. Harriman, V. Heitz, J.-P. Sauvage, J. Phys. Chem. 97 (1993) 5940.

[33] D.G. Johnson, M.P. Niemczyk, D.V. Minsek, G.P. Wiederrecht, W.A. Swec, G.L. Gaines III, M.R. Wasielewski, J. Am. Chem. Soc. 115 (1993) 5692.

[34] I. Rips, J. Jortner, J. Chem. Phys. 87 (1987) 2090. 